\title{
A Two-step Model for the Interpretation of Meaningful Recognition
}

\author{
Miss Kelsey Scalaro, University of Nevada, Reno
}

Kelsey completed her Bachelor's in mechanical engineering at the University of Nevada and then worked in the aerospace industry for a few years. She has since returned to school and is working on her Master's in mechanical engineering alongside her Ph.D. in engineering education at the University of Nevada, Reno. Her research interests are engineering identity and construction for undergraduate, graduate, and career engineers with an emphasis on the construct of recongition.

\section{Ms. Indira Chatterjee, University of Nevada, Reno}

Indira Chatterjee received her M.S. in Physics from Case Western Reserve University, Cleveland, Ohio in 1977 and Ph.D. in Electrical Engineering from the University of Utah, Salt Lake City, Utah in 1981. Indira is Associate Dean of Engineering and Professor of Electrical and Biomedical Engineering at the University of Nevada, Reno. As Associate Dean she oversees undergraduate and graduate education in the college including recruitment, retention, career placement and advising. She serves as chair of the College of Engineering curriculum committee and is a member of the university curriculum committee. Indira has been a faculty member at the University of Nevada, Reno since 1988. She has been primary mentor to several graduate students who are well placed in industry and academics. Her research areas include: Numerical and experimental bioelectromagnetics, and engineering education. Over the past 33 years she has brought in over $\$ 6$ million in research funding from the National Science Foundation, Air Force Office of Scientific Research, Johns Hopkins University, National Institutes of Health, Environmental Protection Agency, Department of Energy and private industry. She is a senior member of the IEEE, and a member of the ASEE, Bioelectromagnetics Society and Society of Women Engineers. She serves on the editorial board of the Bioelectromagnetics Society.

\section{Dr. Ann-Marie Vollstedt, University of Nevada, Reno}

Ann-Marie Vollstedt is a lecturer for the Dean's Office at the University of Nevada, Reno. Dr. Vollstedt completed her dissertation at the University of Nevada, Reno, which focused on exploring the use of statistical process control methods to assess course changes in order to increase student learning in engineering. Dr. Vollstedt teaches courses in engineering design as well as statics and continues to conduct research in engineering education.

\section{Dr. Jeffrey C. LaCombe, University of Nevada, Reno \\ Dr. Adam Kirn, University of Nevada, Reno}

Adam Kirn is an Associate Professor of Engineering Education at University of Nevada, Reno. His research focuses on the interactions between engineering cultures, student motivation, and their learning experiences. His projects involve the study of student perceptions, beliefs and attitudes towards becoming engineers, their problem solving processes, and cultural fit. His education includes a B.S. in Biomedical Engineering from Rose-Hulman Institute of Technology, a M.S. in Bioengineering and Ph.D. in Engineering and Science Education from Clemson University. 


\title{
A Two-Step Model for the Interpretation of Meaningful Recognition
}

\begin{abstract}
This qualitative research paper explores how undergraduate engineering students interpret recognition as meaningful. Presented is the two-step PIER model for the Perception and Interpretation of Engineering Recognition along with two use-cases of the model. Recognition, how students feel others see them as an engineer, has been shown to influence how students see themselves as an engineer. This paper draws on the conceptualization of recognition from the performance/competence, interest, and recognition (PCIR) model for subject related roleidentity. The 16 participants in this study are in a four-year long cohort and take part in focus groups at the end of each semester. At the time of this study, participants have been in three focus group and are in the middle of their second year in an engineering program. Questions about identity and recognition prompt students to share their experiences with how they view themselves and feel they are seen by others. These experiences were used to develop a model to understand the ways perceived recognition is interpreted as meaningful by students. Two usecases of this model are presented to illustrate ways the PIER model may be used by students based on their experience with an engineering identity.
\end{abstract}

\section{Introduction}

This research paper presents a model for the interpretation of recognition by undergraduate engineering students. Identity researchers are encouraging educators to think beyond solely teaching subject content and to include practices that support students seeing themselves as engineers [1]-[5]. Engineering role identity influences student learning, persistence, and motivation [6]-[8], which highlights the need for identity to be developed and maintained through the engineering curriculum. The foundational work of Gee [9, p. 99] frames identity as being strongly influenced by interactions with others and defines identity as "being recognized as a certain 'kind of person' in a given context." The recognition as a certain "kind of person," in this case as an engineer, is important in identity development [1], [3], [10]-[12], and opportunities for recognition to occur must be purposefully integrated into engineering education.

The individualistic culture of engineering [13], paired with its current content-centric curriculum [14], [15] may not easily facilitate opportunities for the development of an engineering identity through recognition. An organized approach driven by established theory is needed to guide the necessary integration of recognition-oriented teaching practices into the existing engineering education curriculum. Despite the critical nature of recognition to identities, little work exists that seeks to expand on the phenomenon of recognition or explore ways it can be supported. A few studies on recognition exist in the K-12 space [16], [17] and engineering education [18], [19], but typically recognition is considered as a small part of much larger identity studies. Current work considers whether students perceive recognition, but little work exists exploring the nuances of what recognition is considered meaningful. More work needs to be done to understand the recognition of engineering identities so that curriculum can be effectively designed to support identity development. 
This paper seeks to add to the limited body of recognition literature in engineering education by qualitatively exploring the ways undergraduate engineering students interpret recognition. Focus group data was collected during participants' first three semesters in an engineering program and is leveraged to develop a two-step model that considers the perception, qualification, and interpretation of meaningful recognition. The model is presented along with two use-cases that illustrate how the model can be used based on participants' time spent with an engineering identity. The research questions examined are:

1) How do undergraduate engineering students evaluate if perceived recognition of their engineering identity is meaningful?

2) How do undergraduate engineering students evaluate recognition based on how long they have spent developing an engineering identity?

\section{Theoretical Framework}

This study leverages the PCIR identity framework [20] which considers three subconstructs: performance/competence, interest, and recognition [12], [21], [22]. This model is popular in engineering education and has informed the development of survey tools frequently used to quantify undergraduate students' engineering role identities [10], [20]. In this study, the construct of recognition, how people believe others view them as an engineer, is used to guide data collection, analysis, and interpretation of results.

In this study, meaningful recognition refers to recognition that develops or maintains an engineering identity. This term was first used in exploring the influence of recognition in the development of STEM identities [12] and has been used to highlight that not all recognition is considered meaningful by students [5], [23]. Meaningful recognition is present "when an individual perceives and internalized this recognition" and considers "what recognition counts for identity development [23, p. 99]." Meaningful recognition comes from meaningful sources, which have been defined as "people whose acceptance of [a student's science identities] matters to her, as a science person [12, p. 1192]." Recognition sources traditionally encapsulate peers, faculty, and family [10], [19] but are extended to include any institution or person whose recognition of an engineering identity matters to the recipient. These definitions guided conversation around the process in which recognition is qualified and interpreted by participants in this study.

This study proposes a model of determining meaningful recognition and examines the proposed model's use as influenced by participants' time spent practicing and developing an engineering identity. Rather than reflect on the "strength" of an engineering identity, this use of participants' experience with an engineering identity is derived from the existing work that considers biographical and time-oriented trajectories of identity development [24], [25].

\section{Methods}

This paper reports qualitative results from an ongoing NSF-funded mixed-methods study (NSF grant \# EHR-1833738) that focuses on a cohort designed to support low-income, academically talented engineering students [26]. This exploratory phenomenological study utilized semi- 
structured focus groups to understand the participants' lived experiences regarding the recognition of engineering identities. This study's longitudinal nature permits additional perspectives on how these perceptions changed as participants gained more experience with their identity. Directed qualitative content analysis was leveraged to support the exploration of a phenomenon and the integration of theoretical frameworks surrounding recognition.

\section{Location and Participants}

This study was conducted at a large, western land-grant, R1 university with initial data collection starting during participants' first semester in the fall of 2019. The study population consisted of 16 undergraduate engineering students who voluntarily applied to be part of a four-year, scholarship-based cohort prior to starting their first semester. Participants were selected based on financial need, academic ability, potential, and letters of recommendation from high school teachers. Table 1 lists participants' pseudonyms, self-reported demographic information, major, and engineering experience before starting college. This sample's composition supports the transferability of the findings to similar populations enrolled in undergraduate engineering programs.

Table 1: Participant pseudonym, self-reported demographic information, and pe-collegiate engineering experience (Major acronyms: $B M E=$ biomedical, $C E=$ civil, $C H E=$ chemical, $C S E=$ computer science, $E E=$ electrical, $M E=$ mechanical, $M S E=$ material science)

\begin{tabular}{|c|c|c|c|c|c|}
\hline Pseudonym & Gender & Race/Ethnicity & Major & $\begin{array}{l}\text { Generation } \\
\text { Status }\end{array}$ & $\begin{array}{l}\text { Prior Engineering } \\
\text { Experience }\end{array}$ \\
\hline Michael & Male & Hispanic & $\mathrm{CE}$ & First & Construction job \\
\hline Jim & Male & White & $\mathrm{ME}$ & First & \\
\hline Kevin & Male & Asian & CSE & First & High school classes \\
\hline Karen & Female & Asian & $\mathrm{CE}$ & Continuing & $\begin{array}{l}\text { Technical high } \\
\text { school }\end{array}$ \\
\hline Andy & Male & Hispanic & BME & First & \\
\hline David & Male & Hispanic & $\mathrm{ME}$ & First & $\begin{array}{l}\text { Engineering } \\
\text { internship }\end{array}$ \\
\hline Toby & Male & Hispanic & $\mathrm{BME}$ & First & \\
\hline Roy & Male & White & $\mathrm{ME}$ & Continuing & $\begin{array}{l}\text { Technical high } \\
\text { school }\end{array}$ \\
\hline Stanley & Male & $\begin{array}{l}\text { White, Middle } \\
\text { Eastern }\end{array}$ & $\mathrm{ME}$ & Continuing & $\begin{array}{l}\text { Technical high } \\
\text { school }\end{array}$ \\
\hline Gabe & Male & White & $\mathrm{CHE}$ & Continuing & High school class \\
\hline Pam & Female & White & $\mathrm{ME}$ & Continuing & \\
\hline Erin & Female & White & CSE & Continuing & $\begin{array}{l}\text { High school class, } \\
\text { camp }\end{array}$ \\
\hline Darryl & Male & $\begin{array}{l}\text { White, American } \\
\text { Indian }\end{array}$ & $\mathrm{ME}$ & Continuing & $\begin{array}{l}\text { Technical high } \\
\text { school }\end{array}$ \\
\hline Oscar & Male & Asian & $\mathrm{EE}$ & First & \\
\hline Todd & Male & Hispanic, White & CSE & Continuing & \\
\hline Kelly & Female & White & MSE & Continuing & Robotics club \\
\hline
\end{tabular}




\section{Data Collection}

To explore experiences of recognition, phenomenology was leveraged as it supports an understanding of the essence of lived experiences through the embodied knowledge and perceptions of participants [27]-[29]. To explore the personal, contextual, and perception-based phenomenon of recognition, semi-structured focus groups were used to collect data. Focus groups were utilized since they facilitated the sharing of group experiences important to the larger study about cohort interactions [30]. Focus groups consisted of four to five participants, lasted about one hour, and were conducted at the end of each semester. The first author led most focus groups with either the second or last author as a secondary interviewer and notetaker. Initial data collection started at the end of participants' first semester in the fall of 2019. This study includes focus group data from participants' first three semesters: fall of 2019 (semester 1), spring of 2020 (semester 2), and fall of 2020 (semester 3). The first focus groups held at the end of the fall semester in 2019 were held in person. The subsequent two sets of focus groups were held via Zoom, an online video platform, due to the switch to remote learning as a result of the COVID-19 pandemic. All focus groups were audio and video recorded, professionally transcribed by Rev.com, and checked for errors before being uploaded to NVivo12.

Guiding questions prompted participants to reflect on their engineering identity, their performance/competence beliefs, and their perceptions of recognition in the past, present, and future to best capture change over time. The guiding question emerged from previous work that quantitatively explored students' engineering identity, performance/competence, and recognition perceptions [10], [31]. Data regarding prior engineering experiences were collected through a question asking to explain why they chose engineering as a major and was collected indirectly as this information was often embedded in student answers to other questions. A selection of questions relevant to this study are presented in Table 2 in the appendix. The focus groups' open-ended nature allowed for follow-up questions and permitted researchers the opportunity to gather rich detail about participants' experiences. To promote responsiveness across focus groups, interviewers stressed the value of capturing participants' experiences even if they were the same as the previous semester.

\section{Data Analysis}

Directed qualitative content analysis facilitated examination of participants' experiences of recognition while leveraging existing identity frameworks. Qualitative content analysis is an approach used to understand the study of a phenomenon [32]. It lends itself to the description interpretation of textual data about participants' lived experiences through codes and themes [33], [34]. Directed or deductive qualitative content analysis does this while extending existing theory to different contexts or situations. In this study, PCIR identity framework's recognition component is leveraged to explore how participants determine recognition as meaningful.

First, transcripts were coded using an inductive descriptive first pass to categorize the data. This coding method is suggested for longitudinal studies or ones with large quantities of data [35]. All transcripts were team-coded by the first, second, and fifth authors who worked to form a consensus on codes. The codebook was developed during the initial coding pass of the first focus group transcripts from fall 2019. This codebook was subsequently leveraged for the coding of 
transcripts from the following semester. As the codebook was refined, the first author recoded previous transcripts using the new or modified codes. Codes pertinent to this study are described in Table 3 of the appendix.

Second, the transcripts and codes underwent a second deductive pass by the first author. This pass considered patterns and ideas across the coded data set to develop underlying ideas or themes [35]. Directed qualitative content analysis facilitates the generation of themes from firstpass codes by a systematic process in which relationships between codes are identified [33]. Themes were shared with the second and fifth author, discussed, and refined until a consensus was reached.

Finally, themes were used to develop a model to understand how participants determined recognition as meaningful through a series of steps or checks. By leveraging the shared stories of the participants, we generated composite use-cases that describe how the evaluation of recognition was influenced by experiences with their engineering identities. The use-cases are presented to illustrate different ways the proposed PIER model may be operationalized by undergraduate engineering students. This model and the associated use-cases were jointly reviewed by the first, second, and fifth authors and discussed with members of the research community that were not associated with this study.

\section{Results}

This paper describes the two-step, sequential Perception and Interpretation of Engineering Recognition (PIER) Model that captures the process in which participants interpret recognition as meaningful. Upon perceiving recognition, participants first qualify the source's ability to recognize their engineering identity before determining if this recognition is warranted based on their perceptions of their competencies. The PIER model is presented in Figure 1. The prerequisite condition regarding the perception of recognition along with its two interpretation steps will be outlined below. We illustrate how undergraduate engineering students with novel and established identities leveraged the PIER model through the presentation of two use-cases. Each use-case includes typical student characteristics and is tied to participants' examples from the study.

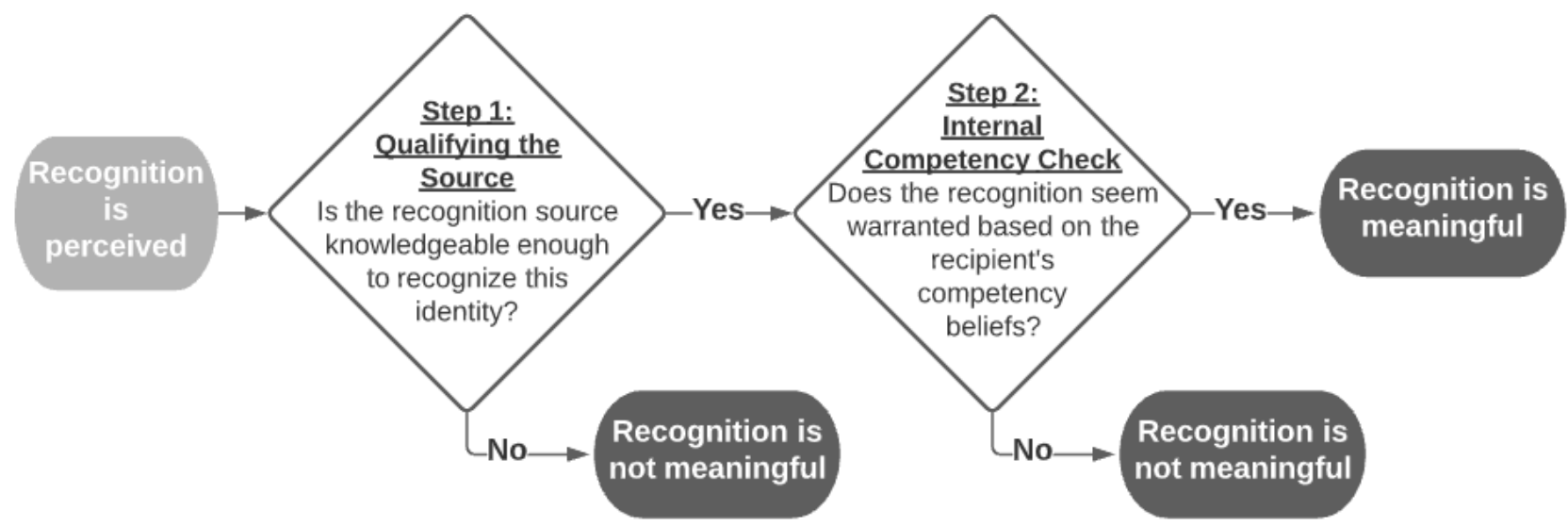

Figure 1: The two-step Perception and Interpretation of Engineering Recognition Model (PIER). Ovals represent a start or end of a process, and diamonds represent a decision. 
Start: Recognition is Perceived

Before participants can determine if recognition is meaningful, they must first perceive recognition as happening. Participants' perceptions of recognition are a necessary pre-condition for the PIER model as it centers on the evaluation of that recognition, not the instance of recognition. These instances of recognition involved social interaction between people or groups of people, and participants described explicit and implicit recognition. Kelly described direct, explicit recognition of an engineering identity with a pre-collegiate memory: "Growing up, people always told me, 'hey, you'd make a good engineer." Participants most often described instances of implicit recognition of their engineering identity. This recognition sometimes centered around being asked to perform engineering-related tasks, as is the case with Roy's answer to how he knew his parents saw him as an engineer: "They have like a math problem they have to do, and they're like, Oh Roy, get over here. Or I always have to fix all the computers in the family and stuff like that." Other instances of implicit perceived recognition included being known by teachers in a large class, observations by family and friends of participants' interest in engineering, or how engineering family members started to share more information with the participant. This was especially true for Erin, whose mother works in computer science: “ $M y$ mom, I'm not really sure either. I think she may slightly ... At least partially, because she does talk to me more recently about what's she doing for work." The examples are a glimpse of the variety of ways participants described perceiving recognition and provide the necessary input for the PIER model. The following two steps describe what participants did with this perceived recognition as they determined if it is or is not meaningful recognition.

\section{Step 1: Qualifying the Source}

If recognition was perceived, participants first considered the recognition source's qualifications and ability to recognize their engineering identity. This qualification step involves how participants viewed the recognition source's knowledge of engineering which influenced perceptions of the recognition's validity. This step focuses on the determination of recognition as potentially meaningful through qualifying the source. Pam does this when she considers a family member with an engineering background:

"But then, like my grandpa was an engineer and he always saw me as like one, even though I was only on my first year. And I don't know if that was just like grandparents being prideful or what, but that always made me feel slightly better cause I'm like, okay. He kind of knows where I'm coming from, of where I am in my process. (Pam, Semester 2)"

Jim also talks about the qualification of recognition from his fellow engineering students: "Most of my friends are doing engineering, so they might also see me as on the way to becoming it because they already know kind of about it (Semester 2)." When participants deemed a source of recognition unqualified to recognize their engineering identity meaningfully, they question the legitimacy of that source's recognition. Gabe starts to unpack how friends and family from his hometown provided less than meaningful recognition: "I'd say a few people probably do, but I don't feel like the people who see me as an engineer fully understand engineering." In these 
instances, recognition from certain sources is perceived but qualified as not meaningful in this first step of the PIER model.

Step 2: Internal Performance/Competence Check

After participants qualified the recognition source, participants evaluated their own performance/competence beliefs while determining if they should accept or reject the recognition. Participants who felt competent enough to warrant the recognition they received discussed it without any qualifying statements and simply accepted the recognition. Participants who rejected recognition appended a qualifier to a description of a time they were recognized. Pam describes an instance she was recognized by meaningful adults, but she felt she did not have the skills for it to be warranted:

"My old activities director came to visit and she's always talking, she's always, yeah, Pam is an engineer. And I'm like, I don't really know that much. Or I go back and one of their props break, and they're like, hey engineer, go fix it. And I'm like, guys, I haven't learned this. Don't look at me (Pam, semester 2)."

Michael also described the rejection of recognition from meaningful sources. Michael worked at a construction-related job before and during college and referenced his experiences there often. In this instance, he described how his coworkers are starting to see him as an engineer, but he does not feel like this recognition counts yet based upon his skills:

"I think I need to finish my school for it to count. Because I just don't... I wouldn't say, 'Oh yeah, I'm an engineer.' Because I don't have the responsibilities that an engineer has right now or anything close to it, that's why I don't see myself as an engineer. I don't have those responsibilities yet, and I don't think I'm ready for those responsibilities just yet. (Michael, Semester 3)"

A few participants provide insight about how certain opportunities facilitated recognition, but their performance/competence beliefs still dictated whether it was determined as meaningful. Darryl, a mechanical engineering student, started a civil engineering research experience during his second semester. When asked to reflect if this experience helped him feel like an engineer, he said: "I feel like it helped [my family] view me as an engineer, but it didn't really help me (semester 3). "When Toby was asked if the recognition he received influenced how he saw himself as an engineer, he mentioned his lack of competencies: "Not really. I know I still have a long way to go, and I feel like my view of myself is more important than how other people view me (semester 2)." After recognition is perceived and determined to come from a qualified source, this competency check is the necessary last step for recognition to be potentially internalized as meaningful toward developing or supporting an engineering identity.

\section{Use-case 1: The novel identity}

This use-case illustrates how the PIER model is used by participants with new or novel engineering identities. Almost all of the participants in this study are reflected by this use-case during their first semester. Most did not consider engineering a likely degree choice until the end of their high school career and had no prior engineering experience. Participants characterized by this use-case typically have a vague definition of what an engineer is or what an engineer does. 
Recent self-identification or self-recognition of engineering identities allowed participants to perceive recognition from many sources. Participants were not selective about who is qualified to recognize this new identity. Of the recognition that is perceived and qualified as potentially meaningful, it is readily accepted by participants' as their views of their

performance/competence pose no barrier. Those described by this use-case accepted recognition both as engineers and as engineers in progress.

A participant who is well represented by this use-case is Pam during her first two semesters. She described herself as always liking math and science but not considering engineering as a major until her senior year making her engineering identity relatively new or novel. Pam described many perceived instances of explicit and implicit recognition from friends, faculty, and family. She did not question the qualifications of these sources in recognizing her engineering identity and was accepting of recognition from non-engineers, as illustrated by her comment: "When you hang out with other majors, it definitely validates a bit. Other people see and you're like, wait, I am kind of a real engineer, look at me." Pam largely accepted all recognition without questioning if it was warranted per her time spent in the program or her current competencies.

Use-case 2: More experience with identity

This use-case describes a participant who has had a little longer to think about and start practicing their engineering identities. For some participants described by this use-case, this time with their engineering identity occurred before college through STEM clubs or engineeringrelated. For most participants described by this use-case, this time with their engineering identity occurred during their first two semesters in their engineering program. This composite use-case describes most participants during their second and third semesters. These participants had a more defined idea of what an engineer is and what an engineer is not. Participants described by this use-case mention fewer situations where they perceive recognition, and of the instances they mention, they are now selective about who can recognize their engineering identities in a meaningful way. Out-of-group peers and non-engineering family members are frequently cited by participants but described as unqualified to meaningfully recognize engineering identities due to a lack of knowledge. Participants considered faculty, practicing engineers, and engineering family members as potential meaningful sources, but instances of recognition from these sources were infrequent. Engineering peers are often mentioned as either meaningful or non-meaningful sources. The evaluation of engineering peers was influenced by whether the participants viewed their peers as engineers or not.

Additionally, recognition from most sources was rejected as participants felt that they did not know enough yet and had a long way to go to become an engineer. Decreased perceptions of performance/competence acted as a barrier to meaningful recognition. Updated definitions of engineering told participants that many previously meaningful sources of recognition did not understand engineering and that they themselves are not yet engineers. Participants readily accepted recognition as engineers-in-progress rather than as engineers.

This use-case well characterizes David's experiences during his third semester. David started college with a strong yet novel engineering identity that was fostered by an engineering internship he started the summer before college. In previous semesters David mentioned feeling 
like an engineer and described how his engineering coworkers saw him as an engineer. In this third-semester focus group, David no longer considered himself an engineer and now described his coworkers as "[seeing him] developing as an engineer but not quite an engineer yet". When asked why he felt less like an engineer, David described how he thought he had a less accurate idea of what engineer was and what it took to be an engineer:

"I saw myself as becoming an engineer in the past. When I'm actually getting into engineering and stuff, I'm seeing how low my learning level of engineering is right now ... next semester, I'm taking a ton of engineering classes, so I feel like that's going to actually get me to this area of being an engineer... There's a lot more to it than what I thought I knew. (David, Semester 3)."

David represents a student who had a reduced sense of recognition and identity due to a refined definition of what it means to be an engineer. Kelly's third-semester experiences were also well characterized by this use-case, especially when she talks about recognition from an uncle who works in aerospace engineering. During her first two semesters, Kelly described how he saw her as an engineer, but in her third-semester focus group she no longer felt this way: "I happened to see [my uncle] actually over summer. I definitely don't think he really sees me as an engineer. He sees me as an engineering student." A large aspect of this use-case is also the increased selectivity of recognition sources.

\section{Discussion}

The PIER model and supporting use-cases characterize how recognition is determined as meaningful and emerged from data that focused on participants' experiences and perceptions of recognition. These results also corroborate and extend theories of engineering role identities that were used to guide this study.

\section{Performance/Competence Influences Recognition}

How participants perceived and interpreted recognition was influenced by their own competency beliefs. The mediating relationship between performance/competence and recognition is already described quantitatively by survey data for engineering participants' math, physics, and science role identities [2], [4]. This relationship was further examined and is determined to be onedirectional with performance/competence mediating recognition by Godwin et al. [10], who posited that "participants who are recognized before they feel competent may not internalize the recognition [10, p. 327]." This facet is best captured by the second step in the proposed model and the experiences of David. It is also suggested that participants' performance/competency beliefs influenced how often they perceived recognition as occurring. Although this study focuses on the interpretation and internalization of recognition, this relationship between recognition and performance/competence may be reflected by how often participants mentioned feeling recognized. Participants characterized by use-case 1 demonstrated high perceptions of competence and also described more instances of recognition overall. Conversely, participants characterized by use-case 2 had muted evaluations of their engineering competencies and were less forthcoming with examples of times they felt recognized. 


\section{Changes in Identity and its constructs}

Godwin and Lee [36] highlighted a drop in engineering recognition beliefs for students after their first year in an engineering program. The different ways participants used the PIER model as influenced by their time with an engineering identity begins to add some insight as to why this drop in recognition may occur. use-case 2 describes participants who perceived less recognition and are less accepting of it than participants characterized by use-case 1 . Most participants represented by use-case 2 were in their third semester, and sophomore aligning with the timeframe the initial drop in recognition is indicated to occur [36].

Quantitative work for recognition considers if students perceive recognition from sources. If existing studies were to describe perceptions of meaningful recognition, values would likely be lower. The PIER model illustrates how perceived recognition is determined to be meaningful through a two-step process. For participants characterized by use-case 2, this model filters out more recognition instances than for participants characterized by use-case 1 . This additional filtering may indicate that the drop in perceived recognition may be accompanied by a corresponding reduction in meaningful recognition sources. There also appears to be a shift in what versions of an engineering identity participants felt were recognized. Participants characterized by use-case 2 were less receptive to recognition "as an engineer" but seemed more ready to accept recognition "as an engineer-in-progress" or "as an engineering student." This change in how they felt others viewed them may also offer insight as to why students experience a drop in recognition "as an engineer" during the time frame typical of participants of this usecase.

\section{Meaningful Sources}

Surveys meant to capture the recognition construct of engineering role identity typically focus on three main sources of recognition: family, peers, and faculty [1], [2], [10], [11], [19], [20]. These groups are common sources of recognition, and the hierarchy of meaningfulness proposed by Rodriquez et al. [19] is supported by the use of the qualifying first step of the model described by use-case 2. However, this study's results present the case for sources of recognition to be expanded, which is driven by the difference between what is being perceived as happening versus what is being perceived as meaningful. In use-case 2, participants qualify recognition from sources differently depending on the sources' knowledge or experience with engineering. Family and peer sources are currently looked at broadly but may be better considered as multiple sources depending on their STEM experience.

Participants ascribed more value to recognition as engineers-in-progress from their engineering peers rather than the frequently perceived instances from non-engineering peers who were deemed unqualified to recognize engineering identities meaningfully. Non-engineering family often filled the same niche as non-engineering peers, while engineering and STEM family members acted as highly desired but rarely accessed sources of meaningful recognition. Beyond expanding previously explored sources of engineering recognition, industry sources may need to be considered along with faculty as highly-valued recognition sources. During their second and third semesters, participants started to mention instances of recognition from these sources as facilitated by job searches, internships, and co-curricular activities. These additional sources 
should be included to capture the breadth of student experiences with recognition as they move beyond their first semesters and start to gain more experience with their engineering identities.

\section{Implications}

The research findings demonstrate a need to expand the ways engineering education researchers have considered recognition. Specifically, this model indicates a need to move beyond the consideration of recognition as being perceived and include how this recognition is interpreted as meaningful. The stories told through the use-cases offer suggestions on what sources should be targeted when designing curriculum meant to support recognition opportunities.

For students characterized by use-case 1 , teaching practices can be designed to facilitate recognition from a broad array of sources. Since students in this use-case are not yet selective about who can recognize their engineering identity, frequent access to recognition from peers and upper-level students may be sufficient. For students characterized by use-case 2, practices need to be developed that permit access to more knowledgeable recognition sources. Peers may still prove useful, but the addition of graduate students, faculty members, and practicing engineers may be most effective in eliciting recognition interpreted as meaningful.

For all students, the second step of the PIER model highlighted the need for competency beliefs to be supported alongside the learning of skills and access to appropriate recognition sources. Participants demonstrated that they need to feel like they have adequate engineering competencies before they are receptive to meaningful recognition. The creation of plentiful recognition opportunities through curriculum may prove fruitless if students regularly reject the recognition based on their competency beliefs. Both need to be supported in curriculum to develop and maintain engineering identities effectively.

\section{Limitations and Future Work}

This study sought to answer how participants determined if recognition is meaningful, but it has several limiting factors. Verdín and Godwin [37] and Godwin and Potvin [3] warned that gathering qualitative recognition data has specific challenges considering how participants are unlikely to share recognition experiences unless explicitly asked. Although this study had a targeted question asking about recognition, the full range of participants' recognition experiences as an engineer may not have been captured. The guiding question, "do others see you as an engineer?" broadly probes recognition and does not target recognition from certain sources or consider if participants feel seen as an engineering student or engineer in progress.

This study sought to understand how recognition was interpreted and internalized by students' but only captures the valuing portion of the internalization process and does not examine how it becomes integrated with other important aspects of how students view themselves. Future work should examine ways recognition is internalized and connected to other aspects of an engineering identity. Additionally, this study solely considered recognition through the PCIR identity framework. Trustworthiness of these results would be improved by evaluating the data using alternative identity theories and future work should seek to consider the PIER model through different theoretical lenses. 
This study also operated within a much larger study that was not specifically designed to facilitate a deep understanding of specific constructs of identity. For this study, focus groups were deemed appropriate for capturing the group dynamic of the cohort and did not appear to inhibit the retelling of positive recognition experiences but the group atmosphere may have inhibited the sharing of uncertain or negative recognition experiences. Future work would benefit from modifications to data collection techniques and the inclusion of more questions. Interviews with a larger breadth of questions should be leveraged to permit a more nuanced understanding of participants' recognition experiences while providing a more comfortable environment to share personal stories without the feeling of judgment from peers. Additionally, the second and third sets of focus groups were conducted during the Spring and Fall semester of 2020 which were impacted by the Covid-19 pandemic. Education during these semesters was conducted using a hybrid format that included both in-person and online classes. Participants had fewer chances to interact with peers and faculty during these semesters which may influence the quantity of perceived recognition and the ways recognition was interpreted. Future work should consider the PIER model and its use-cases for students experiencing traditional, in-person learning during their second and third semesters.

While the participants in this study were academically talented and low-income, these factors were not explicitly considered. Although the population is relatively diverse in terms of racial and educational background, additional social identities should be further examined to understand the PIER model's broader transferability. Conversations about who has access to recognition sources that participants deemed qualified to meaningfully recognize more established engineering identities can also be tied to ideas around privilege and access. This lens may need to be applied when evaluating the perceived recognition entering the PIER model. This study also only considered the experiences of participants during their first three semesters. How participants use the PIER model during the remainder of their engineering programs should be studied so that transferability beyond entry-level students can be assessed. Expanding beyond early populations would add to the body of knowledge presented in the use-cases and can be used to develop curriculum that can facilitate meaningful recognition.

This study examined how students interpreted perceived recognition as meaningful. This study did not consider how non-meaningful recognition may still be supportive to students in other ways. Participants talked about instances of familial pride that they qualified as non-meaningful per the first step of the PIER model but still described how it was supportive in different ways. Recognition cases that do not directly support an engineering identity per this study but still benefit students in other ways should be further investigated.

\section{Conclusion}

The PCIR identity framework guided data collection, analysis, and the interpretation of findings for this study. Participants' experiences with recognition were used to conceptualize a two-step model that considers the perception of recognition occurring, how sources are qualified as capable of recognizing, and the ways competency beliefs influenced the reception of engineering as meaningful. Composite use-cases illustrated the different ways the proposed model was used by participants with novel and more established engineering identities. Those with new identities 
were highly receptive to most recognition, while those with more established identities were typically more selective and less receptive to recognition overall. The results extend existing recognition work in engineering education and present a model that can serve as a useful tool to facilitate future conversations of recognition.

\section{Acknowledgments}

This research was supported by a grant from the National Science Foundation (NSF grant \#EHR-1833738). The authors wish to thank the PRiDE research group for their constructive comments and reviews that improved this article's quality. Specifically, the authors thank Derrick Satterfield and Mackenzie Parker. The authors thank the other members on the NSF grant that helped organize and run the cohort from which this data was collected: Ivy Chin, Joseph Bozsik, Candice Bauer, Meg Fitzgerald, Julia Williams, and the peer mentors. Finally, we would like to thank our participants for their openness in sharing their experiences of recognition.

\section{Works Cited}

[1] Z. Hazari, G. Sonnert, P. M. Sadler, and M.-C. Shanahan, "Connecting high school physics experiences, outcome expectations, physics identity, and physics career choice: A gender study," J. Res. Sci. Teach., vol. 47, no. 8, pp. 978-1003, 2010.

[2] A. Godwin, G. Potvin, Z. Hazari, and R. Lock, "Understanding Engineering Identity Through Structural Equation Modeling," in IEEE Frontiers in Education Conference, 2013.

[3] A. Godwin and G. Potvin, "Fostering female belongingness in engineering through the Lens of critical engineering agency*," Int. J. Eng. Educ., vol. 31, no. 4, pp. 938-952, 2015.

[4] Z. Hazari, C. Cass, and C. Beattie, "Obscuring power structures in the physics classroom: Linking teacher positioning, student engagement, and physics identity development," $J$. Res. Sci. Teach., vol. 52, no. 6, pp. 765-762, 2015.

[5] Z. Hazari and C. Cass, "Towards meaningful physics recognition: What does this recognition actually look like?," Phys. Teach., vol. 56, pp. 442-446, 2018.

[6] A. Godwin and A. Kirn, "Identity-based motivation: Connections between first- year students' engineering role identities and future-time perspectives," J. Eng. Educ., pp. 122, May 2020.

[7] H. M. Matusovich, R. A. Streveler, and R. L. Miller, "Why do students choose engineering? A qualitative, longitudinal investigation of students' motivational values," $J$. Eng. Educ., vol. 99, no. 4, pp. 289-303, 2010.

[8] M. C. Paretti and L. D. Mcnair, "Analyzing the Intersections of Institutional and Discourse Identities in Engineering Work at the Local Level," Eng. Stud., vol. 4, no. 1, pp. 55-78, 2012.

[9] J. P. Gee, "Identity as an analytic lens for research in education," Rev. Res. Educ., vol. 25, pp. 99-125.

[10] A. Godwin, "The development of a measure of engineering identity," in ASEE Annual Conference and Exposition, 2016.

[11] M. A. Godwin, G. Potvin, and Z. Hazari, "The development of critical engineering agency, identity, and the impact on engineering career choices," in ASEE Annual 
Conference and Exposition, 2013.

[12] H. B. Carlone and A. Johnson, "Understanding the science experiences of successful women of color: Science identity as an analytic lens," J. Res. Sci. Teach., vol. 44, no. 8, pp. 1187-1218, Oct. 2007.

[13] H. G. Murzi and L. D. McNair, "Comparative dmensions of disciplinary culture," in ASEE Annual Conference and Exposition, 2015.

[14] M. Eliot and J. Turns, "Constructing professional portfolios: Sense-making and professional identity development for engineering undergraduates," J. Eng. Educ., vol. 100, no. 4, pp. 630-654, 2011.

[15] D. M. Riley, "Aiding and ABETing: The bankruptcy of outcomes-based education as a change strategy," in ASEE Annual Conference and Exposition, 2012.

[16] A. Calabrese Barton, H. Kang, E. Tan, T. B. O'Neill, J. Bautista-Guerra, and C. Brecklin, "Crafting a future in science: tracing middle school girls' identity work over time and space," Am. Educ. Res. J., vol. 50, no. 1, pp. 37-75, Feb. 2013.

[17] H. B. Carlone, C. M. Scott, and C. Lowder, "Becoming (less) scientific: A longitudinal study of students' identity work from elementary to middle school science," J. Res. Sci. Teach., vol. 51, no. 7, pp. 836-869, 2014.

[18] K. L. Tonso, "Student engineers and engineer identity: Campus engineer identities as figured world," Cult. Stud. Sci. Educ., vol. 1, pp. 273-307, Sep. 2006.

[19] S. Rodriguez, K. Cunningham, and A. Jordan, "STEM identity development for latinas: The role of self- and outside recognition," J. Hispanic High. Educ., vol. 18, no. 3, pp. 254-272, Jul. 2019.

[20] A. D. Patrick, M. Borrego, and C. Conner, "A combined model for predicting engineering identity in undergraduate students," in ASEE Annual Conference and Exposition, 2018.

[21] S. Hidi and K. Ann Renninger, "The four-phase model of interest development," Educ. Psychol., vol. 41, no. 2, pp. 111-127, Mar. 2006.

[22] A. Bandura, "Self-efficacy: Toward a unifying theory of behavioral change," Psychol. Rev., vol. 84, no. 2, pp. 191-215, 1977.

[23] Z. Hazari, E. Brewe, R. M. Goertzen, and T. Hodapp, "The Importance of high school physics teachers for female students' physics identity and persistence," Phys. Teach., vol. 55, pp. 96-99, Feb. 2017.

[24] L. McAlpine, C. Amundsen, and G. Turner, "Identity-trajectory: Reframing early career academic experience," Br. Educ. Res. J., vol. 40, no. 6, pp. 952-969, Dec. 2014.

[25] H. S. Becker and J. W. Carper, "The Development of identification with an occupation," 1956.

[26] I. Chatterjee, K. Scalaro, A. Kirn, A.-M. Vollstedt, and J. LaCombe, "S-STEM: Creating retention and engagement for academically talented engineers," in ASEE Annual Conference and Exposition, 2020.

[27] J. W. Creswell, Qualitative inquiry \& research design: Choosing among five approaches, 2nd ed. SAGE Publications Ltd, 2007.

[28] R. Sokolowski, Introduction to Phenomenology. Cambridge University press, 1999.

[29] K. J. Cross and M. C. Paretti, "African American males' experiences on multiracial student teams in engineering," 2020.

[30] J. A. Leydens, B. M. Moskal, and M. J. Pavelich, "Qualitative methods used in the assessment of engineering education," J. Eng. Educ., vol. 93, no. 1, pp. 65-72, 2004.

[31] A. R. Carberry, H. S. Lee, and M. W. Ohland, "Measuring engineering design self- 
efficacy," J. Eng. Educ., vol. 99, no. 1, pp. 71-79, 2010.

[32] S. Elo and H. Kyngäs, "The qualitative content analysis process," J. Adv. Nurs., vol. 62, no. 1, pp. 107-115, Apr. 2008.

[33] H. F. Hsieh and S. E. Shannon, "Three approaches to qualitative content analysis," Qual. Health Res., vol. 15, no. 9, pp. 1277-1288, Nov. 2005.

[34] A. Assarroudi, F. Heshmati Nabavi, M. R. Armat, A. Ebadi, and M. Vaismoradi, "Directed qualitative content analysis: the description and elaboration of its underpinning methods and data analysis process," J. Res. Nurs., vol. 23, no. 1, pp. 42-55, Feb. 2018.

[35] J. Saldaña, The Coding Manual for Qualitative Researchers, 3rd ed. SAGE Publications Ltd, 2016.

[36] A. Godwin and W. C. Lee, "A cross-sectional study of engineering edentity during undergraduate education," in ASEE Annual Conference and Exposition, 2017.

[37] D. Verdín and A. Godwin, "Physics identity promotes alternative careers for firstgeneration college students in engineering," in ASEE Annual Conference and Exposition, 2017.

\section{Appendix:}

Table 2: Relevant focus group questions used for the collection of data used in this study

\begin{tabular}{|c|c|}
\hline Focus Group Question & Target Information \\
\hline Why did you choose engineering as a major? & Pre-college experiences \\
\hline $\begin{array}{c}\text { Are you confident in your ability to understand } \\
\text { engineering/apply engineering/do well in } \\
\text { engineering classes? }\end{array}$ & Performance/Competence \\
\hline $\begin{array}{c}\text { Do you see yourself as an engineer? Has this } \\
\text { changed since last semester? }\end{array}$ & Engineering Identity \\
\hline $\begin{array}{c}\text { Do others see you as an engineer? Who? How do } \\
\text { you know? Has this changed since last semester? }\end{array}$ & Recognition \\
\hline
\end{tabular}

Table 3: Relevant codes used for the analysis of data in this study

\begin{tabular}{|c|c|c|}
\hline Code & Definition & Example \\
\hline $\begin{array}{l}\text { Engineering } \\
\text { Identity }\end{array}$ & $\begin{array}{l}\text { If and how a participant is identifying } \\
\text { as an engineer. }\end{array}$ & "I feel like an engineer." \\
\hline $\begin{array}{l}\text { Performance/ } \\
\text { Competence }\end{array}$ & $\begin{array}{l}\text { Participants' beliefs about their ability } \\
\text { to accomplish certain tasks. }\end{array}$ & $\begin{array}{l}\text { "For now I understand everything that's going } \\
\text { on and I can get a firm grasp of all the } \\
\text { concepts and stuff like that." }\end{array}$ \\
\hline $\begin{array}{l}\text { Major Choice } \\
\text { Influence }\end{array}$ & $\begin{array}{l}\text { What factors participants described as } \\
\text { influencing their major choice. }\end{array}$ & $\begin{array}{l}\text { "I chose computer science engineering, } \\
\text { because I actually studied engineering in high } \\
\text { school." }\end{array}$ \\
\hline $\begin{array}{l}\text { Recognition - } \\
\text { Faculty }\end{array}$ & $\begin{array}{l}\text { Participants' perception of recognition } \\
\text { from faculty }\end{array}$ & $\begin{array}{l}\text { "Like in terms of peers and faculty would } \\
\text { probably view me as an aspiring engineer." }\end{array}$ \\
\hline $\begin{array}{l}\text { Recognition - } \\
\text { Family }\end{array}$ & $\begin{array}{l}\text { Participants' perception of recognition } \\
\text { from family members }\end{array}$ & "My family sees me as an engineer." \\
\hline
\end{tabular}




\begin{tabular}{|c|l|l|}
$\begin{array}{c}\text { Recognition - } \\
\text { Peers }\end{array}$ & $\begin{array}{l}\text { Participants' perception of recognition } \\
\text { from peers }\end{array}$ & $\begin{array}{l}\text { "In terms of other students, yes, probably I'm } \\
\text { one among my friends who are also engineers. } \\
\text { We all think of each other as engineers." }\end{array}$ \\
\hline $\begin{array}{c}\text { Recognition - }- \\
\text { Other }\end{array}$ & $\begin{array}{l}\text { Participants' perception of recognition } \\
\text { from sources not currently included in } \\
\text { engineering identity literature }\end{array}$ & $\begin{array}{l}\text { "[Engineering Company] expects a } \\
\text { professional level of output from me, so I think } \\
\text { they view me as an engineer." }\end{array}$ \\
\hline
\end{tabular}

